\title{
Five-year cost-effectiveness analysis of the European Fans in Training (EuroFIT) physical activity intervention for men versus no intervention
}

Spyros Kolovos ${ }^{1,2}$, Aureliano P. Finch ${ }^{1}$, Hidde P. van der Ploeg ${ }^{3}$, Femke van Nassau ${ }^{3}$, Hana M. Broulikova ${ }^{1}$, Agni Baka', Shaun Treweek ${ }^{4}$, Cindy M. Gray ${ }^{5}$, Judith G. M. Jelsma ${ }^{3}$, Christopher Bunn ${ }^{5}$, Glyn C. Roberts ${ }^{6}$, Marlene N. Silva ${ }^{7,8}$, Jason M. R. Gill ${ }^{9}$, Øystein Røynesdal ${ }^{6,10}$, Willem van Mechelen ${ }^{3}$, Eivind Andersen ${ }^{6}$, Kate Hunt ${ }^{11}$, Sally Wyke ${ }^{5}$ and Judith E. Bosmans ${ }^{1 *}$

\begin{abstract}
Objectives: Increasing physical activity reduces the risk of chronic illness including Type 2 diabetes, cardiovascular disease and certain types of cancer. Lifestyle interventions can increase physical activity but few successfully engage men. This study aims to investigate the 5 year cost-effectiveness of EuroFIT, a program to improve physical activity tailored specifically for male football (soccer) fans compared to a no intervention comparison group.

Methods: We developed a Markov cohort model in which the impact of improving physical activity on five chronic health conditions (colorectal cancer, Type 2 diabetes, coronary heart disease, stroke and depression) and mortality was modelled. We estimated costs from a societal perspective and expressed benefits as quality adjusted life years (QALYs). We obtained data from a 4-country (England, Netherlands, Portugal and Norway) pragmatic randomised controlled trial evaluating EuroFIT, epidemiological and cohort studies, and meta-analyses. We performed deterministic and probabilistic sensitivity analyses to assess the impact of uncertainty in the model's parameter values on the cost-effectiveness results. We used Monte Carlo simulations to estimate uncertainty and presented this using cost-effectiveness acceptability curves (CEACs). We tested the robustness of the base case analysis using five scenario analyses.
\end{abstract}

Results: Average costs over 5 years per person receiving EuroFIT were $€ 14,663$ and per person receiving no intervention $€ 14,598$. Mean QALYs over 5 years were 4.05 per person for EuroFIT and 4.04 for no intervention. Thus, the average incremental cost per person receiving EuroFIT was $€ 65$ compared to no intervention, while the average QALY gain was 0.01 . This resulted in an ICER of $€ 5206$ per QALY gained. CEACs show that the probability of EuroFIT being cost-effective compared to no intervention is $0.53,0.56$ and 0.58 at thresholds of $€ 10,000, € 22,000$ and $€ 34$, 000 per QALY gained, respectively. When using a time horizon of 10 years, the results suggest that EuroFIT is more effective and less expensive compared to (i.e. dominant over) no intervention with a probability of costeffectiveness of 0.63 at a threshold of $€ 22,000$ per QALY gained.

Conclusions: We conclude the EuroFIT intervention is not cost-effective compared to no intervention over a period of 5 years from a societal perspective, but is more effective and less expensive (i.e. dominant) after 10 years. We thus suggest that EuroFIT can potentially improve public health in a cost-effective manner in the long term.

\footnotetext{
* Correspondence: j.e.bosmans@vu.nl

'Department of Health Sciences, Faculty of Science, Vrije Universiteit

Amsterdam, Amsterdam Public Health research institute, Amsterdam, The

Netherlands

Full list of author information is available at the end of the article
}

(c) The Author(s). 2020 Open Access This article is distributed under the terms of the Creative Commons Attribution 4.0 International License (http://creativecommons.org/licenses/by/4.0/), which permits unrestricted use, distribution, and reproduction in any medium, provided you give appropriate credit to the original author(s) and the source, provide a link to the Creative Commons license, and indicate if changes were made. The Creative Commons Public Domain Dedication waiver (http://creativecommons.org/publicdomain/zero/1.0/) applies to the data made available in this article, unless otherwise stated. 


\section{Introduction}

Physical activity decreases the risk of non-communicable diseases such as coronary heart disease, Type 2 diabetes, colorectal cancer, stroke and depression [1-4]. Some benefits from physical activity occur quickly, such as reduced blood pressure, and improved sleep, cognitive function and insulin sensitivity; others, such as increased cardiorespiratory fitness, decreased depressive symptoms, and sustained reduction in blood pressure, only accrue over months or years of increased physical activity [1]. International guidelines demonstrate that substantial health improvements can be achieved by performing moderate to vigorous physical activity at least 150 min per week [5], which equates to at least 450 Metabolic Equivalent of Task minutes (MET-min) per week [6]. Although estimates vary, many adults do not meet these guidelines recommendations [7, 8], resulting in substantial potentially preventable morbidity and mortality $[2,5,9,10]$, as well as high societal and healthcare costs [11].

Increasing physical activity reduces the risk of chronic illness including Type 2 diabetes, cardiovascular disease and certain types of cancer [12-14]. Lifestyle interventions can increase physical activity but few successfully engage men. In response to this, Gray et al. developed a program, Football Fans in Training (FFIT), tailored specifically to men. FFIT aimed to engage and support men to lose weight through dietary change and physical activity by working with predominant constructions of masculinity [15-17]. Based on the results of a pragmatic randomised controlled trial (RCT), FFIT participants lost more weight over 12 months than control participants (mean difference in percentage weight loss 4.36\% (95\% confidence interval (CI) 3.64 to 5.08) [17]. Moreover, weight loss was sustained over 3.5 years of follow-up (mean percentage weight loss from baseline 2.36\% (95\% CI 1.41 to 3.31) [18].

Recently, the European Fans in Training (EuroFIT) lifestyle change program was developed. The EuroFIT program built on the FFIT program, but shifted the focus of the program from weight loss to improving physical activity and reducing sedentary behaviour. EuroFIT was rigorously evaluated in a 4-country RCT [19]. While the EuroFIT program successfully increased the number of daily steps at 12 months, there was no difference in sedentary time between the two groups [20]. However, improvements were observed in secondary outcomes, including body weight, the proportion of participants with a BMI less than $30 \mathrm{~kg} / \mathrm{m}^{2}$, waist circumference, well-being, self-esteem and vitality, and biomarkers of cardiovascular health (i.e. systolic and diastolic blood pressure, fasting insulin and fasting triglycerides). The within-trial cost-effectiveness analysis showed that EuroFIT was not cost-effective compared to a waitlist condition at 12 months follow-up for quality adjusted life years (QALYs) [20]. However, if the observed improvements in physical activity are sustained over time, it is possible that EuroFIT is cost-effective with regard to QALYs in the long term. Because the waiting list comparison group received the EuroFIT program after conclusion of the RCT, longer follow-up within the RCT was unfeasible. Therefore, we used a Markov cohort model to estimate the five-year costeffectiveness of the EuroFIT program compared to no intervention. This is one of the first longer-term costeffectiveness studies evaluating a physical activity program specifically tailored to men.

\section{Methods}

Design

We developed a Markov cohort model with a time horizon of 5 years to estimate the cost-effectiveness of the EuroFIT program from a societal perspective [19]. We chose to use a Markov model due to its flexibility and its ability to handle multiple possible outcomes [21]. We estimated transition probabilities, costs and utilities using data from both the previously conducted EuroFIT RCT and the literature.

\section{The EuroFIT RCT}

The EuroFIT RCT was conducted during 2016 and 2017 in England, The Netherlands, Norway and Portugal. Ethics committees in each of the four countries have approved the study protocol [19]. The RCT was registered with ISRCTN number 81935608.

Details of the EuroFIT RCT can be found in Van Nassau et al. [19] and Wyke et al. [20]. In summary, 15 professional football clubs in England, the Netherlands, Norway, and Portugal recruited 1113 men aged 30-65 with self-reported body mass index (BMI) $\geq 27 \mathrm{~kg} / \mathrm{m} 2$ into the trial using any of social media posting, email invitations to club members, and local press coverage. We describe baseline characteristics of the participating men in Supplementary Table 1.

\section{Interventions}

We designed the EuroFIT program to support men in becoming more physically active. A detailed description of the EuroFIT intervention is available in Van Nassau et al. [19] and Van de Glind et al. [22]. Briefly, the EuroFIT intervention consisted of 12 weekly sessions in groups of 15 to $20 \mathrm{men}$. Sessions lasted for $90 \mathrm{~min}$, and combined classroom discussions with group-based physical activities tailored to the ability of the participants. Club coaches were trained to create a positive motivational climate tailored specifically to men while delivering the intervention. Coaches also taught participants to choose from a 'toolbox' of behavior change techniques, 
and emphasized personally-relevant benefits of behavior change such as being better able to fulfil valued activities and roles.

The comparison group in the RCT was on a waiting list for the 12 months of the RCT. Subsequently, participants in the comparison group were offered the EuroFIT intervention. However, for the current paper we assumed that they received no intervention during the time horizon of the model. Thus, the control group constitutes a no intervention comparison group.

\section{Model structure and population}

We implemented the Markov model in R software. We based the model on previously published physical activity models [23-27] and extended it with a depression health state, as there is evidence of depression being associated with lack of physical activity $[28,29]$. The Markov model comprised nine mutually exclusive health states. Three health states described the activity levels: physically inactive, moderately active and recommended level of physical activity. Five health states covered five health conditions associated with a lack of physical activity: colorectal cancer, coronary heart diseases, stroke, Type 2 diabetes and depression. The absorbing ninth state was death. Figure 1 shows the structure of the Markov model.
The target population was the same as the participants of the EuroFIT RCT. Apart from having a BMI of 27 or more, we assumed the population otherwise to be in good health, which was defined as the absence of any of the five health conditions included in the model. We determined the proportion of participants starting in each activity level based on the proportion of participants meeting inactive (17.5\%), moderately active (10.5\%) and recommended activity (72.0\%) thresholds at baseline in the EuroFIT RCT. At the end of each cycle, participants could remain in their assigned physical activity category, or move to a different category of physical activity, a health condition or death. The cycle length of the model was 1 year. Thus, we assumed that transitions between the different states of the Markov model occurred yearly. We calculated expected costs and QALYs over a time span of 5 years. In the base case analysis, we assumed that the beneficial effect of EuroFIT compared to no intervention on physical activity over 12 months remained stable for the 5 years of the model. We tested this assumption in one of the sensitivity analyses.

\section{Model input parameters}

Table 1 presents the parameters used in the Markov model. As a first line strategy to retrieve information on the association between physical activity levels and individuals' health, we used the 2018 Physical Activity

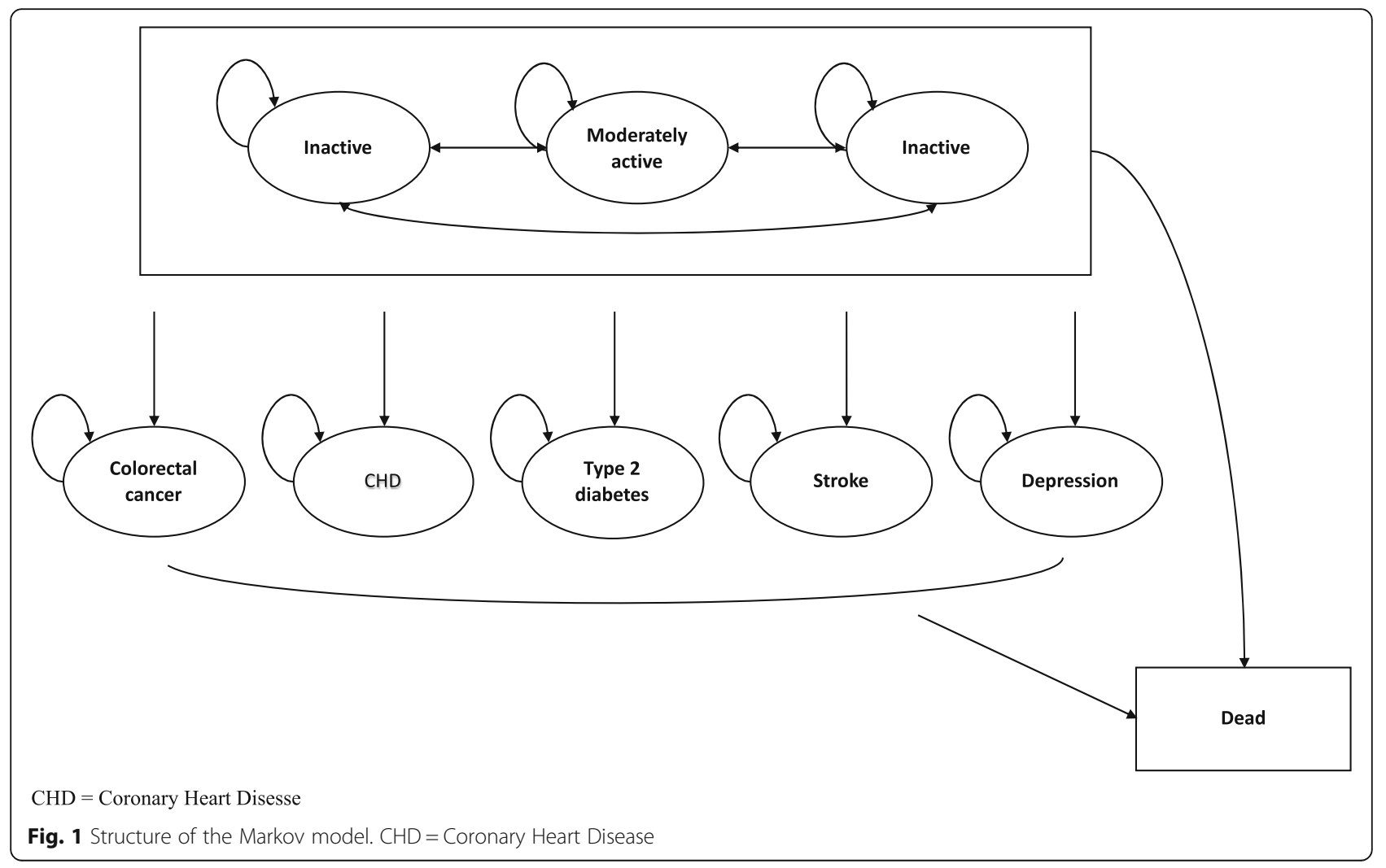


Table 1 Model input parameters

\begin{tabular}{c}
\hline PARAMETERS FOR THE BASE CASE ANALYSIS \\
\hline Values* \\
$\begin{array}{l}\text { Distribution for Source } \\
\text { probabilistic } \\
\text { sensitivity } \\
\text { analysis }\end{array}$
\end{tabular}

\section{Physical activity (transition probabilities at the end of each cycle of 12 months)}

EuroFIT

\begin{tabular}{|c|c|c|c|}
\hline $\begin{array}{l}\text { Inactive to } \\
\text { Inactive }\end{array}$ & 0.18 & $\begin{array}{l}\text { Beta }(\alpha=4.0, \\
\beta=17.0)\end{array}$ & EuroFIT RCT [20] \\
\hline $\begin{array}{l}\text { Inactive to } \\
\text { Moderately } \\
\text { active }\end{array}$ & 0.054 & $\begin{array}{l}\text { Beta }(\alpha=0.34 \\
\beta=5.7)\end{array}$ & EuroFIT RCT [20] \\
\hline $\begin{array}{l}\text { Inactive to } \\
\text { Recommended } \\
\text { activity }\end{array}$ & 0.71 & $\begin{array}{l}\text { Beta }(\alpha=59.4 \\
\beta=19.6)\end{array}$ & EuroFIT RCT [20] \\
\hline $\begin{array}{l}\text { Moderately } \\
\text { active to } \\
\text { Moderately } \\
\text { active }\end{array}$ & 0.042 & $\begin{array}{l}\text { Beta }(\alpha=0.09, \\
\beta=1.9)\end{array}$ & EuroFIT RCT [20] \\
\hline $\begin{array}{l}\text { Moderately } \\
\text { active to Inactive }\end{array}$ & 0.085 & $\begin{array}{l}\text { Beta }(\alpha=0.44, \\
\beta=4.56)\end{array}$ & EuroFIT RCT [20] \\
\hline $\begin{array}{l}\text { Moderately } \\
\text { active to } \\
\text { Recommended } \\
\text { activity }\end{array}$ & 0.82 & $\begin{array}{l}\text { Beta }(\alpha=33.8, \\
\beta=5.2)\end{array}$ & EuroFIT RCT [20] \\
\hline $\begin{array}{l}\text { Recommended } \\
\text { activity to } \\
\text { Recommended } \\
\text { Activity }\end{array}$ & 0.89 & $\begin{array}{l}\text { Beta }(\alpha=357.9, \\
\beta=26.1)\end{array}$ & EuroFIT RCT [20] \\
\hline $\begin{array}{l}\text { Recommended } \\
\text { activity to } \\
\text { Inactive }\end{array}$ & 0.042 & $\begin{array}{l}\text { Beta }(a=0.83, \\
\beta=18.2)\end{array}$ & EuroFIT RCT [20] \\
\hline $\begin{array}{l}\text { Recommended } \\
\text { activity to } \\
\text { Moderately } \\
\text { active }\end{array}$ & 0.023 & $\begin{array}{l}\text { Beta }(\alpha=0.24, \\
\beta=9.8)\end{array}$ & EuroFIT RCT [20] \\
\hline \multicolumn{4}{|l|}{ Vo intervention } \\
\hline $\begin{array}{l}\text { Inactive to } \\
\text { Inactive }\end{array}$ & 0.33 & $\begin{array}{l}\text { Beta }(\alpha=11.5, \\
\beta=21.5)\end{array}$ & EuroFIT RCT [20] \\
\hline $\begin{array}{l}\text { Inactive to } \\
\text { Moderately } \\
\text { active }\end{array}$ & 0.12 & $\begin{array}{l}\text { Beta }(a=1.6 \\
\beta=10.4)\end{array}$ & EuroFIT RCT [20] \\
\hline $\begin{array}{l}\text { Inactive to } \\
\text { Recommended } \\
\text { activity }\end{array}$ & 0.49 & $\begin{array}{l}\text { Beta }(\alpha=25.0, \\
\beta=23.0)\end{array}$ & EuroFIT RCT [20] \\
\hline $\begin{array}{l}\text { Moderately } \\
\text { active to } \\
\text { Moderately } \\
\text { active }\end{array}$ & 0.17 & $\begin{array}{l}\text { Beta }(a=1.5, \\
\beta=6.6)\end{array}$ & EuroFIT RCT [20] \\
\hline $\begin{array}{l}\text { Moderately } \\
\text { active to Inactive }\end{array}$ & 0.19 & $\begin{array}{l}\text { Beta }(\alpha=2.1 \\
\beta=8.0)\end{array}$ & EuroFIT RCT [20] \\
\hline $\begin{array}{l}\text { Moderately } \\
\text { active to }\end{array}$ & 0.58 & $\begin{array}{l}\text { Beta }(\alpha=16.6 \text {, } \\
\beta=10.4)\end{array}$ & EuroFIT RCT [20] \\
\hline
\end{tabular}

Recommended activity
Table 1 Model input parameters (Continued)

\begin{tabular}{|c|c|c|c|}
\hline \multicolumn{4}{|c|}{ PARAMETERS FOR THE BASE CASE ANALYSIS } \\
\hline & Values* & $\begin{array}{l}\text { Distribution for } \\
\text { probabilistic } \\
\text { sensitivity } \\
\text { analysis }\end{array}$ & Source \\
\hline $\begin{array}{l}\text { Recommended } \\
\text { activity to } \\
\text { Recommended } \\
\text { Activity }\end{array}$ & 0.80 & $\begin{array}{l}\text { Beta }(\alpha=290.7, \\
\beta=58.3)\end{array}$ & EuroFIT RCT [20] \\
\hline $\begin{array}{l}\text { Recommended } \\
\text { activity to } \\
\text { Inactive }\end{array}$ & 0.10 & $\begin{array}{l}\text { Beta }(\alpha=4.2, \\
\beta=37.8)\end{array}$ & EuroFIT RCT [20] \\
\hline $\begin{array}{l}\text { Recommended } \\
\text { activity to } \\
\text { Moderately } \\
\text { active }\end{array}$ & 0.064 & $\begin{array}{l}\text { Beta }(\alpha=1.9, \\
\beta=26.1)\end{array}$ & EuroFIT RCT [20] \\
\hline
\end{tabular}
of 12 months)

\begin{tabular}{|c|c|c|c|}
\hline $\begin{array}{l}\text { Inactive to } \\
\text { colorectal cancer }\end{array}$ & 0.015 & Fixed & $\cos M$ study $[30,31]$ \\
\hline $\begin{array}{l}\text { Inactive to heart } \\
\text { diseases }\end{array}$ & 0.011 & Fixed & $\begin{array}{l}\text { Meta-analysis; SALLS } \\
\text { study }[30,32-34]\end{array}$ \\
\hline $\begin{array}{l}\text { Inactive to Type } \\
2 \text { diabetes }\end{array}$ & 0.005 & Fixed & $\begin{array}{l}\text { EPIC-Interact study and } \\
\text { epidemiological study } \\
{[33,35,36]}\end{array}$ \\
\hline $\begin{array}{l}\text { Inactive to } \\
\text { stroke }\end{array}$ & 0.0046 & Fixed & ARIC study [37] \\
\hline $\begin{array}{l}\text { Inactive to } \\
\text { depression }\end{array}$ & 0.010 & Fixed & $\begin{array}{l}\text { Meta-analysis; Health } \\
\text { survey for England and } \\
\text { Scotland }[34,35,38]\end{array}$ \\
\hline $\begin{array}{l}\text { Moderately } \\
\text { active to } \\
\text { colorectal cancer }\end{array}$ & 0.011 & Fixed & $\cos M$ study $[30,31]$ \\
\hline $\begin{array}{l}\text { Moderately } \\
\text { active to heart } \\
\text { disease }\end{array}$ & 0.009 & Fixed & $\begin{array}{l}\text { Meta-analysis; SALLS } \\
\text { study }[30,32-34]\end{array}$ \\
\hline $\begin{array}{l}\text { Moderately } \\
\text { active to Type } 2 \\
\text { diabetes }\end{array}$ & 0.0038 & Fixed & $\begin{array}{l}\text { EPIC-Interact study; } \\
\text { epidemiological study } \\
{[33,35,36]}\end{array}$ \\
\hline $\begin{array}{l}\text { Moderately } \\
\text { active to stroke }\end{array}$ & 0.0033 & Fixed & ARIC study [37] \\
\hline $\begin{array}{l}\text { Moderately } \\
\text { active to } \\
\text { depression }\end{array}$ & 0.0094 & Fixed & $\begin{array}{l}\text { Meta-analysis; Health } \\
\text { survey for England and } \\
\text { Scotland }[34,35,38]\end{array}$ \\
\hline $\begin{array}{l}\text { Recommended } \\
\text { activity to } \\
\text { colorectal cancer }\end{array}$ & 0.0096 & Fixed & $\operatorname{CosM}$ study $[30,31]$ \\
\hline $\begin{array}{l}\text { Recommended } \\
\text { activity to heart } \\
\text { disease }\end{array}$ & 0.008 & Fixed & $\begin{array}{l}\text { Meta-analysis; SALLS } \\
\text { study }[30,32-34]\end{array}$ \\
\hline $\begin{array}{l}\text { Recommended } \\
\text { activity to Type } \\
2 \text { diabetes }\end{array}$ & 0.0033 & Fixed & $\begin{array}{l}\text { EPIC-Interact study; } \\
\text { epidemiological study } \\
{[33,35,36]}\end{array}$ \\
\hline $\begin{array}{l}\text { Recommended } \\
\text { activity to stroke }\end{array}$ & 0.0029 & Fixed & ARIC study [37] \\
\hline
\end{tabular}


Table 1 Model input parameters (Continued)

\begin{tabular}{llll}
\hline PARAMETERS FOR THE BASE CASE ANALYSIS & \\
\hline & Values* & $\begin{array}{l}\text { Distribution for } \\
\text { probabilistic } \\
\text { sensitivity } \\
\text { analysis }\end{array}$ & Source \\
\hline $\begin{array}{l}\text { Recommended } \\
\text { activity to } \\
\text { depression }\end{array}$ & 0.0092 & Fixed & $\begin{array}{l}\text { Meta-analysis; Health } \\
\text { survey for England and } \\
\text { Scotland }[34,38,39]\end{array}$
\end{tabular}

Mortality (transition probabilities at the end of each cycle of 12 months)

\begin{tabular}{|c|c|c|c|}
\hline Inactive to death & 0.016 & Fixed & $\begin{array}{l}\text { Meta-analysis; } \\
\text { epidemiological study } \\
{[73,74,75,76]}\end{array}$ \\
\hline $\begin{array}{l}\text { Moderately } \\
\text { active to death }\end{array}$ & 0.012 & Fixed & $\begin{array}{l}\text { Meta-analysis; } \\
\text { epidemiological study } \\
{[73,74,75,76]}\end{array}$ \\
\hline $\begin{array}{l}\text { Recommended } \\
\text { activity to death }\end{array}$ & 0.010 & Fixed & $\begin{array}{l}\text { Meta-analysis; } \\
\text { epidemiological study } \\
{[73,74,75,76]}\end{array}$ \\
\hline $\begin{array}{l}\text { Colorectal } \\
\text { cancer to death }\end{array}$ & 0.092 & Fixed & $\begin{array}{l}\text { International Cancer } \\
\text { Benchmarking } \\
\text { partnership registries } \\
{[40]}\end{array}$ \\
\hline $\begin{array}{l}\text { Coronary heart } \\
\text { disease to death }\end{array}$ & 0.002 & Fixed & WONDER registry [41] \\
\hline $\begin{array}{l}\text { Type } 2 \text { diabetes } \\
\text { to death }\end{array}$ & 0.015 & Fixed & ZODIAC study [42] \\
\hline Stroke to death & 0.400 & Fixed & MONICA registry [43] \\
\hline Depression to & 0.030 & Fixed & STIRLING registry [44] \\
\hline
\end{tabular}

Utility values

$\begin{array}{lcll}\begin{array}{l}\text { Inactive - Base } \\ \text { case }\end{array} & 0.909 & \begin{array}{l}\text { Beta }(\alpha=3.0, \\ \beta=0.38)\end{array} & \text { EuroFIT RCT [20] } \\ \begin{array}{l}\text { Moderately } \\ \text { active - Base } \\ \text { case }\end{array} & 0.919 & \begin{array}{l}\text { Beta }(\alpha=5.1, \\ \beta=0.51)\end{array} & \text { EuroFIT RCT [20] } \\ \begin{array}{l}\text { Recommended } \\ \text { activity - Base } \\ \text { case }\end{array} & 0.922 & \begin{array}{l}\text { Beta }(a=5.1, \\ \beta=0.43)\end{array} & \text { EuroFIT RCT [20] } \\ \begin{array}{l}\text { Colorectal } \\ \text { cancer }\end{array} & 0.786 & \text { Fixed } & \text { Systematic review [45] } \\ \begin{array}{l}\text { Coronary hearth } \\ \text { disease }\end{array} & 0.735 & \text { Fixed } & \begin{array}{l}\text { Longitudinal survey } \\ \text { [46] }\end{array} \\ \begin{array}{l}\text { Stroke } \\ \text { Longitudinal survey }\end{array} \\ \begin{array}{l}\text { Type 2 diabetes } \\ \text { Depression }\end{array} & 0.785 & \text { Fixed } & \begin{array}{l}\text { Systematic review [48] } \\ \text { Systematic review [49] }\end{array}\end{array}$

Annual costs per person according to the societal perspective (€ 2017)

\begin{tabular}{|c|c|c|c|}
\hline Inactive & 2436 & $\begin{array}{l}\text { Gamma } \\
\text { (shape =0.19, } \\
\text { scale = 12,658) }\end{array}$ & EuroFIT RCT [20] \\
\hline $\begin{array}{l}\text { Moderately } \\
\text { active }\end{array}$ & 1506 & $\begin{array}{l}\text { Gamma } \\
\text { (shape =0.22, } \\
\text { scale }=6920)\end{array}$ & EuroFIT RCT [20] \\
\hline $\begin{array}{l}\text { Recommended } \\
\text { activity }\end{array}$ & 1997 & $\begin{array}{l}\text { Gamma } \\
\text { (shape =0.24, } \\
\text { scale }=8222)\end{array}$ & EuroFIT RCT [20] \\
\hline
\end{tabular}

Table 1 Model input parameters (Continued)

\begin{tabular}{|c|c|c|c|}
\hline \multicolumn{4}{|c|}{ PARAMETERS FOR THE BASE CASE ANALYSIS } \\
\hline & Values* & $\begin{array}{l}\text { Distribution for } \\
\text { probabilistic } \\
\text { sensitivity } \\
\text { analysis }\end{array}$ & Source \\
\hline $\begin{array}{l}\text { Colorectal } \\
\text { cancer }\end{array}$ & 34,085 & Fixed & $\begin{array}{l}\text { Cross sectional study; } \\
\text { Health insurance } \\
\text { registry }[50,51]\end{array}$ \\
\hline $\begin{array}{l}\text { Coronary heart } \\
\text { disease }\end{array}$ & 5239 & Fixed & Economic burden [52] \\
\hline Type 2 diabetes & 5907 & Fixed & Economic burden [53] \\
\hline Stroke & 24,979 & Fixed & Economic burden [54] \\
\hline Depression & 6819 & Fixed & $\begin{array}{l}\text { Cost-effectiveness } \\
\text { analysis [55] }\end{array}$ \\
\hline EuroFIT program & 260 & Fixed & EuroFIT RCT [20] \\
\hline
\end{tabular}

\section{PARAMETERS FOR THE SENSITIVITY ANALYSES}

Utility values

$\begin{array}{lccl}\begin{array}{l}\text { Inactive }- \\ \text { Literature } \\ \text { utilities }\end{array} & 0.80 & \text { Fixed } & \begin{array}{l}\text { Economic evaluation } \\ {[24]}\end{array} \\ \begin{array}{l}\text { Moderately } \\ \text { active }-\end{array} & 0.87 & \text { Fixed } & \begin{array}{l}\text { Economic evaluation } \\ \text { Literature } \\ \text { utilities }\end{array} \\ \begin{array}{llll}\text { Recommended } & 0.91 & \text { Fixed } & \\ \text { activity - } \\ \text { Literature }\end{array} & & & \text { Economic evaluation } \\ \text { utilities } & & & {[24]}\end{array}$

Annual costs per person according to the healthcare perspective (€ 2017)

\begin{tabular}{|c|c|c|c|}
\hline Inactive & 1107 & $\begin{array}{l}\text { Gamma } \\
(\text { shape }=0.10 \\
\text { scale }=10,924)\end{array}$ & EuroFIT RCT [20] \\
\hline $\begin{array}{l}\text { Moderately } \\
\text { active }\end{array}$ & 594 & $\begin{array}{l}\text { Gamma } \\
\text { (shape =0.35, } \\
\text { scale =1707) }\end{array}$ & EuroFIT RCT [20] \\
\hline $\begin{array}{l}\text { Recommended } \\
\text { activity }\end{array}$ & 747 & $\begin{array}{l}\text { Gamma } \\
(\text { shape }=0.19 \\
\text { scale }=4040)\end{array}$ & EuroFIT RCT [20] \\
\hline $\begin{array}{l}\text { Colorectal } \\
\text { cancer }\end{array}$ & 25,346 & Fixed & $\begin{array}{l}\text { Cross sectional study; } \\
\text { Health insurance } \\
\text { registry }[50,51]\end{array}$ \\
\hline $\begin{array}{l}\text { Coronary heart } \\
\text { disease }\end{array}$ & 1954 & Fixed & Economic burden [52] \\
\hline Type 2 diabetes & 3089 & Fixed & Economic burden [53] \\
\hline Stroke & 18,750 & Fixed & Economic burden [54] \\
\hline Depression & 966 & Fixed & $\begin{array}{l}\text { Cost-effectiveness } \\
\text { analysis [55] }\end{array}$ \\
\hline
\end{tabular}

Guidelines Advisory Committee Scientific Report [6]. The report includes the broadest systematic literature review available on the association between physical activity and adverse outcomes, including risk of 
cardiovascular disease, cancers and all-cause mortality. As it does not specifically focus on the population investigated in EuroFIT, we used this review to identify studies including male individuals aged between 30 to 65 years.

To identify additional studies on the natural course of physical activity, we conducted targeted literature searches using PubMed, Web of Science and Google Scholar. We only included studies written in English. Whenever a study provided data that were relevant to populate the model, we screened the reference list to identify and retrieve additional evidence. We also conducted targeted literature searches to retrieve information on resource use and utilities associated with physical activity levels. Whenever possible, we retrieved evidence from studies conducted in European countries related to a mainly Caucasian, male, overweight population, aged between 30 and 65 years old. If these were not available, we used comparable evidence from normal weight individuals, from the USA, or for male population of an older age as model inputs.

\section{Physical activity}

Table 1 presents the changes in self-reported physical activity for the EuroFIT and no intervention groups. We estimated yearly probabilities of transitioning between physical activity levels or staying in the original activity level using the EuroFIT pragmatic RCT [20] and made them conditional on the transition probabilities of progressing to a condition or death. The EuroFIT RCT assessed physical activity both objectively with the activPAL monitor (model activPALTM micro; PAL Technologies Ltd., Glasgow, UK) and subjectively using the self-reported International Physical Activity Questionnaire (IPAQ short form), which assesses walking, other moderate intensity physical activity and vigorous intensity physical activity [56]. Both measures of physical activity improved in the EuroFIT arm of the RCT. We used self-reported physical activity in our model for two main reasons. First, although subjectively reported physical activity rates almost certainly over-estimate the actual level of physical activity, the current physical activity guidelines are primarily built on epidemiologic studies that used self-report measures. Secondly, there are still too few studies that estimate the association between objective measures of physical activity and health.

We defined the three activity categories according to the self-reported MET-min per week of the EuroFIT participants. MET-min per week is an index capturing the total amount of all physical activity, where one MET is defined as the rate of energy expenditure at rest [5]. We classified participants reporting < 200 MET-min per week as physically inactive, participants reporting between 200 and 450 MET-min per week as moderately physically active, and participants reporting $>450$ METmin per week as meeting desired levels of physical activity, according to physical activity guidelines $[5,6,57]$. We estimated the probability of moving to a higher or lower physical activity category in the EuroFIT RCT for the intervention and the comparison group separately as the percentage of participants in one activity group at baseline moving to a different activity group at 12 months follow up.

\section{Health conditions and mortality}

To estimate the yearly probability of developing each of the five health conditions included in the model, we used incidence and relative risk data from the literature. To estimate the probability of death associated with the five conditions, we used annual mortality rates based on a particular condition. To estimate the probability of death associated with different levels of physical activity, we used mortality rates and relative risk data. The sources are described in more detail in Table 1; they included meta-analyses, epidemiological studies and registries [30-33, 35-44, 55, 57-60].

\section{Utilities}

We used QALYs as the effect measure in the costeffectiveness analysis. QALYs are calculated by multiplying the time participants spend in a given health state with a utility value that represents the health-related quality of life (HRQoL) associated with that health state. We obtained utility values for the inactive, moderately active and recommended activity states from the EuroFIT RCT [20]. The EuroFIT RCT used the five level version of the EuroQol questionnaire (EQ-5D) to estimate utilities, which is the most widely used measure to do this [61]. We obtained utilities for the chronic conditions covered in the model from three systematic reviews and two longitudinal studies [45-49].

\section{Costs}

We estimated costs of the EuroFIT program using a bottom-up approach, and included costs of personnel responsible for preparation, coordination, administration, recruitment and program delivery, and materials. We estimated costs generated in the different activity states based on the EuroFIT RCT [20]. We obtained costs of the conditions modelled from three economic burden studies, one cross-sectional study, one registry study and one economic evaluation [50-55]. In accordance with the societal perspective employed in this study, we included both healthcare costs and lost productivity costs. We adjusted costs using the consumer price index to the year 2017 [62] and, whenever needed, we converted costs into Euros $(€)$ for the year 2017 using purchasing 
power parities [63], as recommended in international guidelines [21].

\section{Cost-effectiveness analysis}

We distributed a cohort of 10,000 participants in each of the treatment arms over the three activity categories at the start of the time horizon modelled. As recommended by the National Institute for Health and Care Excellence (NICE), we discounted costs and effects at 3.5\% [64]. We calculated incremental cost-effectiveness ratios (ICERs) by dividing the difference in total costs between the EuroFIT intervention and the comparison group by the difference in total QALYs. We consider the intervention cost-effective if the ICER is smaller than a pre-defined willingness-to-pay threshold. For the current study, we used the commonly accepted NICE threshold of $£ 20,000$ to $£ 30,000$ per QALY gained [64], which corresponds to $€ 22,000$ to $€ 34,000$ per QALY gained.

\section{Sensitivity analyses Probabilistic sensitivity analyses}

We performed a probabilistic sensitivity analysis (PSA) for the base case analysis and each of the four scenario analyses. For parameters that were directly observed in the EuroFIT RCT, we estimated a sampling distribution based on the variance around the point estimates for these parameters. Next, we used Monte Carlo simulation $(25,000$ simulations) to randomly select values from the specified distributions. We used beta distributions for transition probabilities, beta distributions for utilities and gamma distributions for costs (Table 1). Using the 25,000 simulations, we estimated $95 \%$ credibility intervals around incremental costs and QALYs based on the 2.5 and $97.5 \%$ percentiles. Finally, we estimated costeffectiveness acceptability curves (CEACs) to present the probability of EuroFIT being cost-effective compared to no intervention at different willingness to pay thresholds.

\section{Deterministic sensitivity analyses}

We performed deterministic sensitivity analyses in which the discount rates for costs and effects were varied $(0$ and 5\%). This was undertaken for costs and effects separately, and for costs and effects simultaneously.

\section{Scenario analyses}

We tested the robustness of the base case findings by performing four scenario analyses. For all scenarios, we evaluated the deterministic impact on the ICER point estimate and the probabilistic impact on the probability of cost-effectiveness at different willingness to pay ratios.

First, we extended the time horizon of the model to 10 years to assess longer term effects of the intervention while assuming that the effect of EuroFIT was maintained over a period of 10 years. Second, we ran the model from the healthcare perspective, as this is preferred by health technology assessment bodies such as NICE [64]. Third, we obtained utility values for the inactive, moderately active and recommended activity states from the literature, and specifically from a previously conducted economic evaluation of an intervention to improve physical activity [24]. We did this sensitivity analysis, because differences in utility values between physical activity levels in the literature are larger than the ones we found in the EuroFIT RCT. Fourth, we reran the model while limiting the beneficial effect of EuroFIT on physical activity to the first year, hence after the first year the transition probabilities from the no intervention group were used.

\section{Results}

\section{Cost-effectiveness analysis}

Table 2 reports the results of the base-case analysis. Total costs for the EuroFIT group were $€ 146,629,613$ per 10,000 participants as compared to $€ 145,975,002$ in the no intervention group. This resulted in an incremental cost for the cohort of $€ 654,611$, equivalent to $€ 65$ per participant. QALYs in the EuroFIT group were 40,431 compared to 40,405 in the no intervention group, resulting in a small gain of 126 QALYs $(+0.31 \%)$ in favour of EuroFIT, which is equivalent to 0.013 QALYs gained per participant. EuroFIT generates 195 QALYs more than no intervention based on time spent in the health states describing the physical activity levels (the 'healthy' states). In addition, the EuroFIT group generates 69 QALYs less than no intervention based on time spent in the health states describing the associated health conditions (the 'disease' states). The resulting ICER was $€ 5206$ per QALY gained for EuroFIT in comparison with no intervention.

\section{Probabilistic sensitivity analysis}

Figure 2 presents the distribution of incremental costeffect pairs for the base case analysis based on the 25, 000 simulations in the probabilistic sensitivity analysis. The cost-effectiveness plane shows that EuroFIT is more effective and more costly than no intervention, and that there is considerable uncertainty around the ICER.

From the CEAC (Fig. 3), it emerges that the probability that EuroFIT is cost-effective compared with no intervention, is 0.53 at a threshold of $€ 10,000$ per QALY. This probability increases to 0.56 and 0.58 at thresholds of $€ 22,000$ and $€ 34,000$ per QALY gained, respectively.

\section{Sensitivity analyses}

\section{Deterministic sensitivity analyses}

Figure 4 reports the results for the deterministic sensitivity analyses in which the discount rates were varied from 
Table 2 Cost effectiveness results for the base case and scenario analyses

\begin{tabular}{|c|c|c|c|c|c|c|}
\hline Analysis & $\begin{array}{l}\text { Treatment } \\
\text { arm }\end{array}$ & $\begin{array}{l}\text { Total costs }(€ \\
\text { 2017) }\end{array}$ & $\begin{array}{l}\text { Total } \\
\text { QALYS }\end{array}$ & Incremental Cost & $\begin{array}{l}\text { Incremental } \\
\text { QALYs }\end{array}$ & ICER \\
\hline \multirow[t]{2}{*}{ Base case } & EuroFIT & $€ 146,629,613$ & 40,531 & \multirow[t]{2}{*}{$€ 654,611(-73,893,166 ; 81,741,624)$} & \multirow[t]{2}{*}{$126(-1999 ; 2527)$} & \multirow[t]{2}{*}{5206} \\
\hline & $\begin{array}{l}\text { No } \\
\text { intervention }\end{array}$ & $€ 145,975,002$ & 40,405 & & & \\
\hline \multirow[t]{2}{*}{ Healthcare perspective } & EuroFIT & $€ 72,489,139$ & 40,531 & \multirow[t]{2}{*}{$€ 496,731(-37,026,528 ; 35,107,767)$} & \multirow[t]{2}{*}{$126(-2026 ; 2537)$} & \multirow[t]{2}{*}{3951} \\
\hline & $\begin{array}{l}\text { No } \\
\text { intervention }\end{array}$ & $€ 71,992,408$ & 40,405 & & & \\
\hline \multirow[t]{2}{*}{ Utility values from the literature } & EuroFIT & $€ 146,629,613$ & 39,767 & \multirow[t]{2}{*}{$€ 654,611(-73,893,166 ; 81,741,624)$} & \multirow[t]{2}{*}{$564(-68 ; 1106)$} & \multirow[t]{2}{*}{1161} \\
\hline & $\begin{array}{l}\text { No } \\
\text { intervention }\end{array}$ & $€ 145,975,002$ & 39,203 & & & \\
\hline \multirow{2}{*}{$\begin{array}{l}\text { EuroFIT effectiveness lasts only } 1 \\
\text { year }\end{array}$} & EuroFIT & $€ 147,631,100$ & 40,427 & \multirow{2}{*}{$\begin{array}{l}€ 1,759,289(-19,869,112 ; 25,189 \\
547)\end{array}$} & \multirow[t]{2}{*}{$52(-555 ; 725)$} & \multirow[t]{2}{*}{33,997} \\
\hline & $\begin{array}{l}\text { No } \\
\text { intervention }\end{array}$ & $€ 145,871,811$ & 40,375 & & & \\
\hline \multirow[t]{2}{*}{ Time horizon 10 years } & EuroFIT & $€ 303,622,814$ & 71,010 & \multirow{2}{*}{$\begin{array}{l}-€ 2,595,287(-128,814,119 ; 137,269, \\
728)\end{array}$} & \multirow[t]{2}{*}{$373(-3254 ; 4534)$} & \multirow[t]{2}{*}{ Dominant } \\
\hline & $\begin{array}{l}\text { No } \\
\text { intervention }\end{array}$ & $€ 306,218,101$ & 70,636 & & & \\
\hline
\end{tabular}

QALY Quality-Adjusted Life-Year, ICER Incremental Cost-Effectiveness Ratio

the base case analysis. The figure shows that the effect on the ICER point estimates was limited with impacts ranging from $-35 \%$ (discount rate for costs and effects $0 \%$ ) to $15 \%$ (discount rate for costs and effects $5 \%$ ).

\section{Scenario analyses}

Figure 4 also presents the deterministic results of the scenario analyses. When the time horizon of the model was extended to 10 years, the ICER became negative due to a negative difference in costs $(-€ 2,595,287)$ and a positive difference in QALYs gained (373 QALYs gained), indicating that EuroFIT is dominant over no intervention. Employing a healthcare perspective decreased the ICER by $24 \%$. Using literature estimates for the utilities associated with the different physical activity levels resulted in 39,767 and 39,203 QALYs in the EuroFIT and no intervention group, respectively. Thus, the total number of QALYs gained was 564 in the EuroFIT group, or 0.056 QALY per participant. The ICER was $€ 1161$ per QALY gained, indicating a decrease of $78 \%$

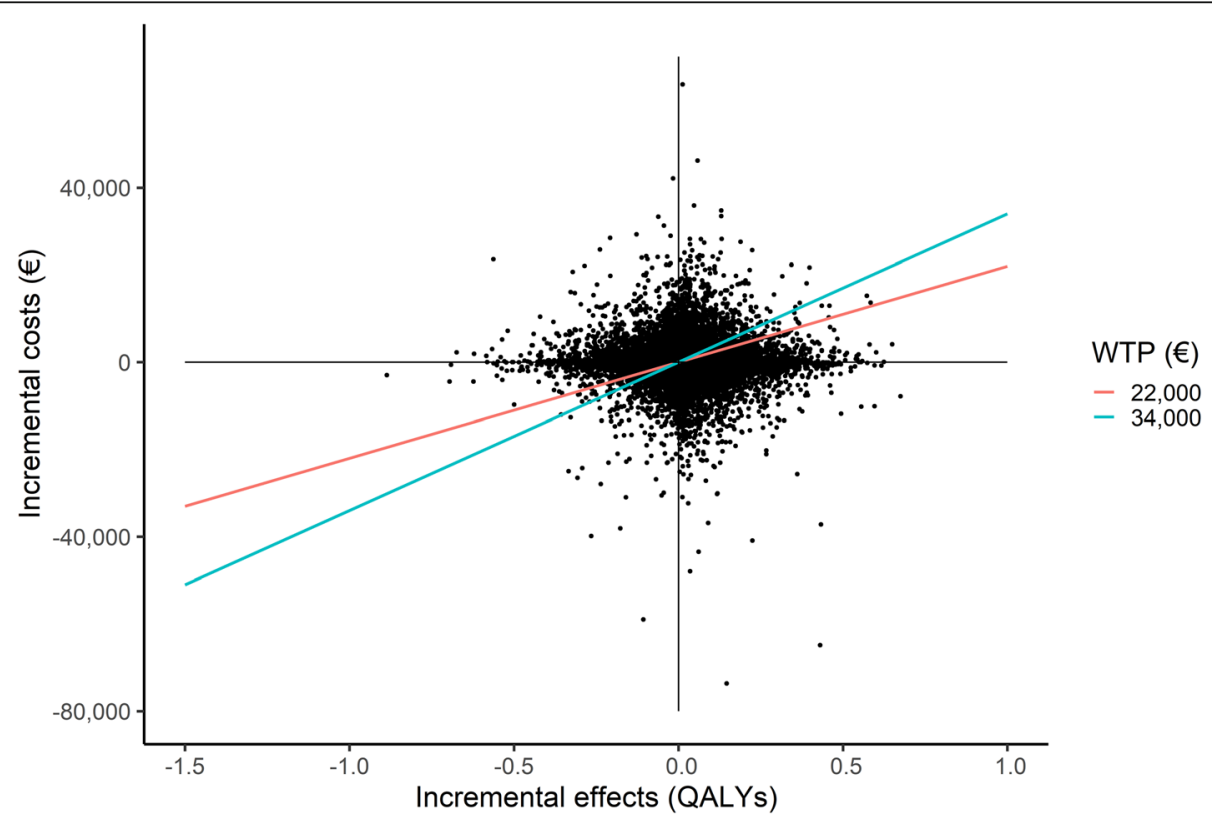

Fig. 2 Cost-effectiveness plane for the base case analysis. WTP = Willingness-To-Pay; QALY = Quality-Adjusted Life-Year 


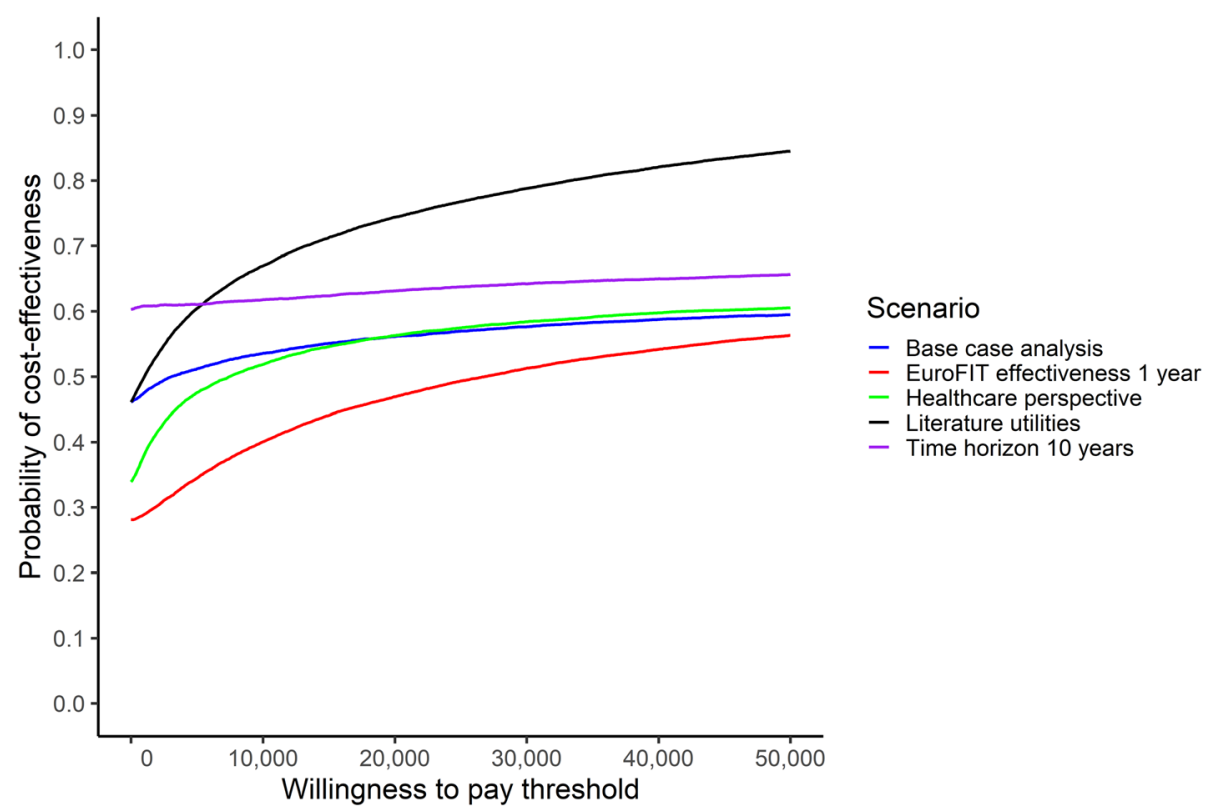

Fig. 3 Cost-effectiveness acceptability curves for the base case analysis and the scenario analyses

compared with the base case analysis. The assumption that the effect of EuroFIT lasted only for 1 year, resulted in an increase of the difference in costs between EuroFIT and no intervention $(€ 1,759,289)$ and a decrease in QALYs gained (52 QALYs gained). As a result, the ICER increased by $553 \%$ from $€ 5206$ to $€ 33,996$ per QALY gained. Although there was a considerable impact on the point estimate of the ICER for all scenarios considered, the probability of EuroFIT being cost-effective compared with no intervention changed less. When assuming oneyear effects of EuroFIT, the probability was 0.47 at a threshold of $€ 22,000$ per QALY gained, when using a healthcare perspective the probability was 0.57 , and when modelling a time horizon of 10 years the probability was 0.63 (Fig. 3). In the scenario using literature utilities, the probability that EuroFIT is costeffective compared to no intervention was 0.75 at a threshold of $€ 22,000$ per QALY gained (Fig. 3).

\section{Discussion}

In this study, we evaluated the long-term costeffectiveness of EuroFIT compared to no intervention from a societal perspective. EuroFIT was slightly more effective and slightly more expensive than no intervention, resulting in an ICER of $€ 5206$ per QALY gained. Although this point estimate of the ICER lies well below the commonly accepted thresholds of between $€ 22,000$ to $€ 34,000$ per QALY gained, the probability of cost-

Percentage change in ICER

Discount rate costs and effects $0 \%$
Discount rate costs and effects $5 \%$
Discount rate effects $0 \%$
Discount rate effects $5 \%$
Discount rate costs $0 \%$
Discount rate costs $5 \%$
Follow-up 10 year
Healthcare perspective
Literature utilities
EurofiT effect 1 year
Fig. 4 Tornado diagram showing the change in incremental cost-effectiveness ratios between the base case analysis and the scenario and
deterministic sensitivity analyses


effectiveness at these thresholds was only 56 to $58 \%$. Using a 10-year time horizon and assuming 1 year effects of EuroFIT had the largest impact on the ICER point estimates. However, the change in the probability of cost-effectiveness was largest in the scenario where utility values from the literature were used for the three physical activity levels. Given this evidence, we consider the EuroFIT intervention not to be cost-effective compared to no intervention on a time horizon of 5 years, but cost-effective on a time horizon of 10 years.

When interpreting the findings of the current study, it is important to consider the fact that at baseline already $72 \%$ of the participants were at recommended levels of activity. Since we modelled only effects on physical activity in the current study, this leaves little room for improvement. However, EuroFIT resulted in considerable improvements in other outcomes, such as weight and biomarkers of cardiometabolic health, as well [20]. As these improvements might also positively impact health benefits, it is likely that our study underestimates the cost-effectiveness of the intervention.

The utility values derived from the EuroFIT RCT were similar for the three levels of physical activity. In addition, utility values reported by the EuroFIT RCT participants in all three physical activity states were around 0.90 , suggesting that the participants had high quality of life already. This is in contrast with utility values reported in previous studies, which have shown that the individuals following the recommended guidelines for physical activity have increased utility values [65-67]. This might reflect problems with the construct validity of the EQ-5D-5 L in the population investigated. That is, the EQ-5D-5 L might miss important dimensions relevant to assess health benefits resulting from behavioural interventions, examples of which can be energy, vitality, enthusiasm, sleeping, relationships and satisfaction. Using multi-attribute approaches that include such domains, as suggested by Wildman and Wildman may prove to be helpful when evaluating complex interventions like EuroFIT $[65,68]$.

Our findings are in line with previous studies evaluating the cost-effectiveness of intervention programs targeted to improve physical activity. For example, a systematic review showed that primary care and the community interventions, such as pedometers as motivational tools, motivational interviews, brief advice, GP prescription and GP counselling, appeared to be costeffective, with ICERs ranging between $€ 1161$ and $€ 16$, 666 per QALY gained [31, 67]. The ICER of $€ 5206$ per QALY gained we found in the current study compares very well with these estimates.

This study has a number of important strengths. It employed a previously used Markov model24,27 and extended it with a health state for depression. This allows for a broader assessment of the effects and costs associated with physical inactivity compared to previous studies. Moreover, a large number of alternative scenarios was evaluated using probabilistic sensitivity analyses, which allowed for an in-depth exploration of the uncertainty in assumptions and parameters used in the model. Finally, whenever possible, parameter estimates were selected from published meta-analyses to avoid the suggestion of "cherry-picking".

Despite these strengths, the study also has some limitations. Although the most prevalent conditions associated with a lack of physical activity were included in the model, a number of other conditions have not been included (e.g. hypertension). We expect that this has led to an underestimation of the cost-effectiveness of the intervention rather than an overestimation. Also, it was not possible to have more than one disease at the same time in the model, whereas having for example diabetes increases the risk of cardiovascular disease as well. This was a pragmatic choice to keep the model as simple as possible. We expect that taking these comorbid risks into account could increase the potential costeffectiveness of the intervention. In addition, there is a risk of double-counting the risk of mortality, as part of the mortality in the different physical activity states is probably associated with one of the five diseases included in the model. However, we expect that this effect is limited considering the relatively low risk of mortality for the different levels of physical activity compared to the mortality risks associated with the different health conditions included in the model. Finally, we assumed that the benefits of the intervention were sustained over the five-year period. Although empirical evidence on the sustainability of health behaviour changes is limited, studies indicate that interventions that target both physical activity and diet, are more likely to result in longterm changes in health behaviours [32, 68]. Moreover, results from the FFIT RCT, on which EuroFIT was based, showed that lifestyle changes were maintained over 3.5 years [18]. However, since we do not have reliable evidence on the retention of the changes in physical activity, we decided to limit the time horizon of the model to 5 years. When we assumed that effects disappear after 1 year, the ICER increased greatly $(+553 \%)$. However, when we increased the time horizon to 10 years the ICER was considerably lower (-233\%).

Despite these limitations, this study is one of the first evaluating the longer-term cost-effectiveness of a novel lifestyle intervention that focussed on increasing physical activity and was tailored to men specifically. Further research should identify whether the EQ-5D-5 L is suitable to measure quality of life in relatively healthy men; data from the EuroFIT RCT suggests that its descriptive 
nature was not sensitive enough to distinguish between different levels of physical activity. Finally, longitudinal studies should show whether and to which extent effects on physical activity are sustained beyond the time horizon commonly employed in RCTs to better estimate long-term cost-effectiveness of interventions aimed at improving physical activity.

Based on the current study, we conclude the EuroFIT intervention not to be cost-effective compared to no intervention over a period of 5 years from a societal perspective. However, when using a time horizon of 10 years the results suggest that EuroFIT is more effective and less expensive compared to (i.e. dominant over) no intervention. We thus suggest that EuroFIT can potentially improve public health in a cost-effective manner in the long term.

\section{Supplementary information}

Supplementary information accompanies this paper at https://doi.org/10. 1186/s12966-020-00934-7.

Additional file 1: Table S1. Baseline characteristics of the population included in the EuroFIT trial reported as mean (SD) or N(\%).

Additional file 2:.

\section{Acknowledgements}

Not applicable.

\section{Authors' contributions}

JEB led the overall design of the study. APF, SK and AB collected the necessary data. APF, SK, JEB and FN analyzed the data. APF, SK and JEB prepared the manuscript. All authors assisted in interpreting the final results and critically revising the manuscript for intellectual content, including reading and approving it. All authors read and approved the final manuscript.

\section{Funding}

This project has received funding from the European Union's Seventh Framework Program for research, technological development, and demonstration under grant agreement number 602170. The funders had no role in study design, data collection and analysis, decision to publish, or preparation of the manuscript.

\section{Availability of data and materials}

Data from the study are available for secondary analysis. Applications to access the data can be made by contacting the corresponding author of this paper.

\section{Ethics approval and consent to participate}

Not applicable (no individual participant data were used in this study).

\section{Consent for publication}

Not applicable.

\section{Competing interests}

The authors declare that they have no competing interests.

\section{Author details}

${ }^{1}$ Department of Health Sciences, Faculty of Science, Vrije Universiteit Amsterdam, Amsterdam Public Health research institute, Amsterdam, The Netherlands. ${ }^{2}$ Nuffield Department of Orthopaedics, Rheumatology and Musculoskeletal Sciences, University of Oxford, Oxford, UK. ${ }^{3}$ Amsterdam UMC, VU medical center, Department of Public and Occupational Health, Amsterdam Public Health research institute, Van der Boechorststraat 7,
NL-1081 BT Amsterdam, The Netherlands. ${ }^{4}$ Health Services Research Unit, University of Aberdeen, Aberdeen, UK. Institute of Health and Wellbeing, College of Social Sciences, University of Glasgow, Glasgow, UK. ${ }^{6}$ Department of coaching and psychology, Norwegian School of Sport Science, Oslo, Norway. ${ }^{7}$ CIPER, Faculdade de Motricidade Humana, Universidade de Lisboa, Lisbon, Portugal . ${ }^{8}$ Faculdade de Educação Física e Desporto, Universidade Lusófona de Humanidades e Tecnologias, Lisbon, Portugal. ${ }^{9}$ Institute of Cardiovascular and Medical Sciences, College of Medical, Veterinary and Life Sciences, University of Glasgow, Glasgow, UK. ${ }^{10}$ Department of Teacher Education, NLA University College, Bergen, Norway. ${ }^{11}$ Institute for Social Marketing and Health, University of Stirling, Stirling, UK.

Received: 19 March 2019 Accepted: 17 February 2020

Published online: 04 March 2020

\section{References}

1. Piercy KL, Troiano RP, Ballard RM, et al. The Physical Activity Guidelines for Americans. JAMA. 2018;320(19):2020-8. https://doi.org/10.1001/jama.2018. 14854.

2. Lee I-M, Shiroma EJ, Lobelo F, et al. Effect of physical inactivity on major non-communicable diseases worldwide: an analysis of burden of disease and life expectancy. Lancet Lond Engl. 2012;380(9838):219-29. https://doi. org/10.1016/S0140-6736(12)61031-9.

3. Varghese T, Schultz WM, McCue AA, et al. Physical activity in the prevention of coronary heart disease: implications for the clinician. Heart Br Card Soc. 2016;102(12):904-9. https://doi.org/10.1136/heartjnl-2015-308773.

4. Pedersen BK, Saltin B. Exercise as medicine - evidence for prescribing exercise as therapy in 26 different chronic diseases. Scand J Med Sci Sports. 2015;25(Suppl 3):1-72. https://doi.org/10.1111/sms.12581.

5. WHO. NCDs | Global Action Plan on Physical Activity 2018-2030: More Active People for a Healthier World.; 2018. http://www.who.int/ncds/prevention/ physical-activity/global-action-plan-2018-2030/en/. Accessed 12 Sept 2019.

6. Scientific Report - 2018 Physical Activity Guidelines.; 2018. https://health. gov/paguidelines/second-edition/report/. Accessed 12 Sept 2019.

7. Loyen A, Van Hecke L, Verloigne M, et al. Variation in population levels of physical activity in European adults according to cross-European studies: a systematic literature review within DEDIPAC. Int J Behav Nutr Phys Act. 2016;13(1):72. https://doi.org/10.1186/s12966-016-0398-2.

8. Guthold R, Stevens GA, Riley LM, Bull FC. Worldwide trends in insufficient physical activity from 2001 to 2016: a pooled analysis of 358 populationbased surveys with 1.9 million participants. Lancet Glob Health. 2018;6(10): e1077-86. https://doi.org/10.1016/\$2214-109X(18)30357-7.

9. Kokkinos P, Sheriff H, Kheirbek R. Physical Inactivity and Mortality Risk. Cardiol Res Pract. 2011. https://doi.org/10.4061/2011/924945.

10. Knight JA. Physical inactivity: associated diseases and disorders. Ann Clin Lab Sci. 2012:42(3):320-37.

11. Ding $D$, Lawson $K D$, Kolbe-Alexander $T L$, et al. The economic burden of physical inactivity: a global analysis of major non-communicable diseases. Lancet. 2016;388(10051):1311-24. https://doi.org/10.1016/S01406736(16)30383-X.

12. Wahid A, Manek N, Nichols M, et al. Quantifying the Association Between Physical Activity and Cardiovascular Disease and Diabetes: A Systematic Review and Meta-Analysis. J Am Heart Assoc. 2016;5:9. https://doi.org/10. 1161/JAHA.115.002495

13. Smith AD, Crippa A, Woodcock J, Brage S. Physical activity and incident type 2 diabetes mellitus: a systematic review and dose-response metaanalysis of prospective cohort studies. Diabetologia. 2016;59(12):2527-45. https://doi.org/10.1007/s00125-016-4079-0.

14. Kyu HH, Bachman VF, Alexander LT, et al. Physical activity and risk of breast cancer, colon cancer, diabetes, ischemic heart disease, and ischemic stroke events: systematic review and dose-response meta-analysis for the Global Burden of Disease Study 2013. BMJ. 2016;354:i3857. https://doi.org/10.1136/ bmj.i3857.

15. Wyke S, Hunt K, Gray CM, et al. Football Fans in Training (FFIT): a randomised controlled trial of a gender-sensitised weight loss and healthy living programme for men - end of study report. 2015. doi:doi:https://doi. org/10.3310/phr03020.

16. Gray CM, Hunt K, Mutrie N, et al. Football Fans in Training: the development and optimization of an intervention delivered through professional sports clubs to help men lose weight, become more active and adopt healthier 
eating habits. BMC Public Health. 2013;13(1):232. https://doi.org/10.1186/ 1471-2458-13-232.

17. Hunt K, Wyke S, Gray CM, et al. A gender-sensitised weight loss and healthy living programme for overweight and obese men delivered by Scottish Premier League football clubs (FFIT): a pragmatic randomised controlled trial. Lancet. 2014:383(9924):1211-21. https://doi.org/10.1016/S01406736(13)62420-4

18. Gray CM, Wyke S, Zhang $R$, et al. Long-term weight loss trajectories following participation in a randomised controlled trial of a weight management programme for men delivered through professional football clubs: a longitudinal cohort study and economic evaluation. Int I Behav Nutr Phys Act. 2018;15(1):60. https://doi.org/10.1186/s12966-018-0683-3.

19. van Nassau F, van der Ploeg HP, Abrahamsen F, et al. Study protocol of European Fans in Training (EuroFIT): a four-country randomised controlled trial of a lifestyle program for men delivered in elite football clubs. BMC Public Health. 2016;16(1):598. https://doi.org/10.1186/s12889016-3255-y.

20. Wyke S, Bunn C, Andersen E, et al. The effect of a programme to improve men's sedentary time and physical activity: The European Fans in Training (EuroFIT) randomised controlled trial. PLoS Med. 2019;16(2):e1002736. https://doi.org/10.1371/journal.pmed.1002736.

21. Briggs A, Sculpher M, Claxton K. Decision Modelling for Health Economic Evaluation. Oxford, New York: Oxford University Press; 2006.

22. van de Glind I, Bunn C, Gray CM, et al. The intervention process in the European Fans in Training (EuroFIT) trial: a mixed method protocol for evaluation. Trials. 2017;18(1):356. https://doi.org/10.1186/s13063-017-2095-0.

23. Anokye NK, Lord J, Fox-Rushby J. Is brief advice in primary care a costeffective way to promote physical activity? Br I Sports Med. 2014;48(3):2026. https://doi.org/10.1136/bjsports-2013-092897.

24. Frew EJ, Bhatti M, Win K, et al. Cost-effectiveness of a community-based physical activity programme for adults (Be Active) in the UK: an economic analysis within a natural experiment. Br J Sports Med. 2014;48(3):207-12. https://doi.org/10.1136/bjsports-2012-091202.

25. Galani C, Al M, Schneider H, Rutten FFH. Uncertainty in decision-making: value of additional information in the cost-effectiveness of lifestyle intervention in overweight and obese people. Value Health J Int Soc Pharmacoeconomics Outcomes Res. 2008;11(3):424-34. https://doi.org/10. 1111/j.1524-4733.2007.00284.x.

26. Gulliford MC, Charlton J, Bhattarai N, Charlton C, Rudisill C. Impact and costeffectiveness of a universal strategy to promote physical activity in primary care: population-based cohort study and Markov model. Eur J Health Econ HEPAC Health Econ Prev Care. 2014;15(4):341-51. https://doi.org/10.1007/ s10198-013-0477-0.

27. Roux L, Pratt M, Tengs TO, et al. Cost effectiveness of community-based physical activity interventions. Am J Prev Med. 2008;35(6):578-88. https:// doi.org/10.1016/j.amepre.2008.06.040.

28. Dogra S, Macintosh L, O'Neill C, et al. The association of physical activity with depression and stress among post-secondary school students: A systematic review. Ment Health Phys Act. 2018;14:146-56. https://doi.org/10. 1016/j.mhpa.2017.11.001

29. Siddiqui F, Lindblad U, Bennet L. Physical inactivity is strongly associated with anxiety and depression in Iraqi immigrants to Sweden: a crosssectional study. BMC Public Health. 2014;14:502. https://doi.org/10.1186/ 1471-2458-14-502.

30. Li J, Siegrist J. Physical activity and risk of cardiovascular disease--a metaanalysis of prospective cohort studies. Int J Environ Res Public Health. 2012; 9(2):391-407. https://doi.org/10.3390/ijerph9020391.

31. Larsson SC, Rutegård J, Bergkvist L, Wolk A. Physical activity, obesity, and risk of colon and rectal cancer in a cohort of Swedish men. Eur J Cancer. 2006; 42(15):2590-7. https://doi.org/10.1016/j.ejca.2006.04.015.

32. Sundquist K, Qvist J, Johansson SE, Sundquist J. The long-term effect of physical activity on incidence of coronary heart disease: a 12-year follow-up study. Prev Med. 2005;41(1):219-25. https://doi.org/10.1016/j.ypmed.2004.09. 043.

33. InterAct Consortium, Ekelund U, Palla L, et al. Physical activity reduces the risk of incident type 2 diabetes in general and in abdominally lean and obese men and women: the EPIC-InterAct Study. Diabetologia. 2012;55(7): 1944-52. https://doi.org/10.1007/s00125-012-2532-2.

34. Hamer M, O'Donovan G, Lee I-M, Stamatakis E. The 'weekend warrior' physical activity pattern: how little is enough? Br J Sports Med. 2017;51(19): 1384-5. https://doi.org/10.1136/bjsports-2017-097538.
35. Andersen LB. Relative risk of mortality in the physically inactive is underestimated because of real changes in exposure level during follow-up. Am J Epidemiol. 2004;160(2):189-95. https://doi.org/10.1093/aje/kwh195.

36. Ringborg A, Lindgren $P$, Martinell M, Yin DD, Schön S, Stålhammar J. Prevalence and incidence of Type 2 diabetes and its complications 19962003--estimates from a Swedish population-based study. Diabet Med J Br Diabet Assoc. 2008;25(10):1178-86. https://doi.org/10.1111/j.1464-5491.2008. 02541.x.

37. Autenrieth CS, Evenson KR, Yatsuya H, Shahar E, Baggett C, Rosamond WD. Association between physical activity and risk of stroke subtypes: the atherosclerosis risk in communities study. Neuroepidemiology. 2013;40(2): 109-16. https://doi.org/10.1159/000342151.

38. Schuch FB, Vancampfort D, Firth J, et al. Physical Activity and Incident Depression: A Meta-Analysis of Prospective Cohort Studies. Am J Psychiatry. 2018;175(7):631-48. https://doi.org/10.1176/appi.ajp.2018.17111194.

39. Löllgen H, Böckenhoff A, Knapp G. Physical activity and all-cause mortality: an updated meta-analysis with different intensity categories. Int I Sports Med. 2009;30(3):213-24. https://doi.org/10.1055/s-0028-1128150.

40. Coleman MP, Forman D, Bryant $\mathrm{H}$, et al. Cancer survival in Australia, Canada, Denmark, Norway, Sweden, and the UK, 1995-2007 (the International Cancer Benchmarking Partnership): an analysis of population-based cancer registry data. Lancet Lond Engl. 2011;377(9760):127-38. https://doi.org/10.1016/ S0140-6736(10)62231-3.

41. Wilmot KA, O'Flaherty M, Capewell S, Ford ES, Vaccarino V. Coronary Heart Disease Mortality Declines in the United States From 1979 Through 2011: Evidence for Stagnation in Young Adults, Especially Women. Circulation. 2015;132(11):997-1002. https://doi.org/10.1161/CIRCULATIONAHA.115. 015293.

42. Hendriks SH, van Hateren KJJ, Groenier KH, et al. Sex differences in survival of patients with type 2 diabetes in primary care (ZODIAC-50). BMJ Open. 2017;7(10):e015870. https://doi.org/10.1136/bmjopen-2017-015870.

43. Brønnum-Hansen H, Davidsen M, Thorvaldsen P. Danish MONICA Study Group. Long-term survival and causes of death after stroke. Stroke. 2001; 32(9):2131-6.

44. Gilman SE, Sucha E, Kingsbury M, Horton NJ, Murphy JM, Colman I. Depression and mortality in a longitudinal study: 1952-2011. CMAJ Can Med Assoc J J Assoc Medicale Can. 2017;189(42):E1304-10. https://doi.org/10. 1503/cmaj.170125.

45. Jeong K, Cairns J. Systematic review of health state utility values for economic evaluation of colorectal cancer. Health Econ Rev. 2016;6(1):36. https://doi.org/10.1186/s13561-016-0115-5.

46. Lacey E, Walters S. Continuing inequality: gender and social class influences on self perceived health after a heart attack. J Epidemiol Community Health. 2003:57(8):622-7. https://doi.org/10.1136/jech.57.8.622.

47. Pickard AS, Johnson JA, Feeny DH, Shuaib A, Carriere KC, Nasser AM. Agreement between patient and proxy assessments of health-related quality of life after stroke using the EQ-5D and Health Utilities Index. Stroke. 2004;35(2):607-12. https://doi.org/10.1161/01.STR.0000110984.91157.BD.

48. Beaudet A, Clegg J, Thuresson P-O, Lloyd A, McEwan P. Review of utility values for economic modeling in type 2 diabetes. Value Health J Int Soc Pharmacoeconomics Outcomes Res. 2014;17(4):462-70. https://doi.org/10. 1016/j.jval.2014.03.003.

49. Kolovos S, Bosmans JE, van Dongen JM, et al. Utility scores for different health states related to depression: individual participant data analysis. Qual Life Res. 2017;26(7):1649-58. https://doi.org/10.1007/s11136-017-1536-2.

50. Haug U, Engel S, Verheyen F, Linder R. Estimating colorectal cancer treatment costs: a pragmatic approach exemplified by health insurance data from Germany. PLoS One. 2014;9(2):e88407. https://doi.org/10.1371/ journal.pone.0088407.

51. Färkkilä $\mathrm{N}$, Torvinen $\mathrm{S}$, Sintonen $\mathrm{H}$, et al. Costs of colorectal cancer in different states of the disease. Acta Oncol Stockh Swed. 2015;54(4):454-62. https://doi.org/10.3109/0284186X.2014.985797.

52. Liu JLY, Maniadakis N, Gray A, Rayner M. The economic burden of coronary heart disease in the UK. Heart. 2002;88(6):597-603 https://www.ncbi.nlm.nih. gov/pmc/articles/PMC1767465/. Accessed 16 Oct 2018.

53. Hex N, Bartlett C, Wright D, Taylor M, Varley D. Estimating the current and future costs of Type 1 and Type 2 diabetes in the UK, including direct health costs and indirect societal and productivity costs. Diabet Med J Br Diabet Assoc. 2012;29(7):855-62. https://doi.org/10.1111/j.1464-5491.2012.03698.X.

54. Xu X-M, Vestesson E, Paley $L$, et al. The economic burden of stroke care in England, Wales and Northern Ireland: Using a national stroke register to 
estimate and report patient-level health economic outcomes in stroke. Eur Stroke J. 2018;3(1):82-91. https://doi.org/10.1177/2396987317746516.

55. Warmerdam L, Smit F, van Straten A, Riper H, Cuijpers P. Cost-utility and cost-effectiveness of internet-based treatment for adults with depressive symptoms: randomized trial. J Med Internet Res. 2010;12(5):e53. https://doi. org/10.2196/jmir.1436

56. Craig CL, Marshall AL, Sjöström M, et al. International physical activity questionnaire: 12-Country reliability and validity. Med Sci Sports Exerc. 2003; 35(8):1381-95. https://doi.org/10.1249/01.MSS.0000078924.61453.FB.

57. Weggemans RM, Backx FJG, Borghouts L, et al. The 2017 Dutch Physical Activity Guidelines. Int J Behav Nutr Phys Act 2018;15. doi:https://doi.org/10. 1186/s12966-018-0661-9.

58. Feng $\mathrm{Q}$, Zhang $\mathrm{Q}, \mathrm{Du}$ Y, Ye Y, He Q. Associations of physical activity, screen time with depression, anxiety and sleep quality among Chinese college freshmen. PLoS One. 2014;9(6):e100914. https://doi.org/10.1371/journal. pone. 0100914

59. Wannamethee SG, Shaper AG. Physical Activity and the Prevention of Stroke. J Cardiovasc Risk. 1999;6(4):213-6. https://doi.org/10.1177/ 204748739900600404

60. Hamer M, Biddle SJH, Stamatakis E. Weekend warrior physical activity pattern and common mental disorder: a population wide study of 108,011 British adults. Int J Behav Nutr Phys Act. 2017;14(1):96. https://doi.org/10. 1186/s12966-017-0549-0.

61. Richardson Jeffrey, Mckie John, Bariola E. Multiattribute Utility Instruments and Their Use. In: Encyclopedia of Health Economics. ; 2014:341-357. doi: https://doi.org/10.1016/B978-0-12-375678-7.00505-8.

62. StatLine. https://opendata.cbs.nl/statline/\#/CBS/nl/. Accessed 12 Sept 2019.

63. PPP. OECD (2016), Purchasing power parities (PPP) (indicator). doi: https:// doi.org/10.1787/1290ee5a-en (Accessed 31 Oct 2016).

64. National Institute for Health and Care Excellence. National Institute for Health and Care Excellence. Guide to the Methods of Technology Appraisal 2013 [Internet]. London: National Institute for Health and Care Excellence (NICE); 2013. http://www.ncbi.nlm.nih.gov/books/NBK395867/. Accessed 12 Sept 2019.

65. Wildman J, Wildman JM. Combining Health and Outcomes Beyond Health in Complex Evaluations of Complex Interventions: Suggestions for Economic Evaluation. Value Health J Int Soc Pharmacoeconomics Outcomes Res. 2019;22(5):511-7. https://doi.org/10.1016/j.jval.2019.01.002.

66. Cobiac LJ, Vos T, Barendregt JJ. Cost-effectiveness of interventions to promote physical activity: a modelling study. PLoS Med. 2009;6(7):e1000110. https://doi.org/10.1371/journal.pmed.1000110.

67. Gc V, Wilson ECF, Suhrcke M, Hardeman W, Sutton S. VBI Programme Team. Are brief interventions to increase physical activity cost-effective? A systematic review. Br J Sports Med. 2016;50(7):408-17. https://doi.org/10. 1136/bjsports-2015-094655

68. Dombrowski SU, Knittle K, Avenell A, Araújo-Soares V, Sniehotta FF. Long term maintenance of weight loss with non-surgical interventions in obese adults: systematic review and meta-analyses of randomised controlled trials. BMJ. 2014;348:g2646. https://doi.org/10.1136/bmj.g2646.

\section{Publisher's Note}

Springer Nature remains neutral with regard to jurisdictional claims in published maps and institutional affiliations.

Ready to submit your research? Choose BMC and benefit from:

- fast, convenient online submission

- thorough peer review by experienced researchers in your field

- rapid publication on acceptance

- support for research data, including large and complex data types

- gold Open Access which fosters wider collaboration and increased citations

- maximum visibility for your research: over $100 \mathrm{M}$ website views per year

At $\mathrm{BMC}$, research is always in progress.

Learn more biomedcentral.com/submissions 